\title{
AREA-WIDE ERADICATION OF THE INVASIVE EUROPEAN GRAPEVINE MOTH Lobesia botrana IN CALIFORNIA, USA
}

\author{
G. S. SIMMONS ${ }^{1}$, L. VARELA ${ }^{2}$, M. DAUGHERTY ${ }^{3}$,

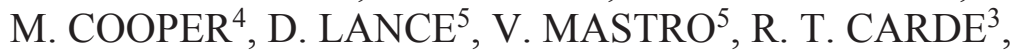 \\ A. LUCCHI $^{6}$, C. IORIATTI ${ }^{7}$, B. BAGNOLI ${ }^{8}$, R. STEINHAUER ${ }^{9}$, \\ R. BROADWAY ${ }^{10}$, B. STONE SMITH ${ }^{10}$, K. HOFFMAN $^{11}$, \\ G. CLARK $^{12}$, D. WHITMER ${ }^{13}$ AND R. JOHNSON ${ }^{14}$ \\ ${ }^{1}$ USDA-APHIS-PPQ, CPHST California Station and Otis Lab, 1636 E. Alisal Road, \\ Salinas, California 93905, USA; Gregory.S.Simmons@aphis.usda.gov \\ ${ }^{2}$ University of California Cooperative Extension, Santa Rosa, California 95403, \\ USA \\ ${ }^{3}$ Department of Entomology, Riverside, California 92521, USA \\ ${ }^{4}$ University of California Cooperative Extension, Napa, California 94559, USA \\ ${ }^{5}$ Retired, USDA-APHIS-PPQ, CPHST 1398 W. Truck Rd, Buzzards Bay, \\ Massachusetts 02542, USA \\ ${ }^{6}$ Department of Agriculture, Food \& Environment, University of Pisa, 56124 Pisa, \\ Italy \\ ${ }^{7}$ Center For Technology Transfer, FEM-IASMA, 38010 San Michele all'Adige, \\ Trento, Italy \\ ${ }^{8}$ Department for Innovation in Biological, Agro-Food and Forest Systems, \\ University of Tuscia, via San Camillo de Lellis, 01100 Viterbo, Italy \\ ${ }^{9}$ Wineland Consulting, St. Helena, California 94574, USA \\ ${ }^{10}$ USDA-APHIS-PPQ-FO, Sacramento, California 95814, USA \\ ${ }^{11}$ CDFA, Street 2800 Gateway Oaks Drive, Sacramento, California 95833, USA \\ ${ }^{12}$ Napa County Department of Agriculture, Napa, California 94559, USA \\ ${ }^{13}$ Retired, Napa County Department of Agriculture, Napa, California 94559, USA \\ ${ }^{14}$ USDA-APHIS-PPQ, 4700 River Rd, Riverdale, Maryland 20737, USA
}

J. Hendrichs, R. Pereira and M. J. B. Vreysen (eds.), Area-Wide Integrated Pest Management: Development and Field Application, pp. 581-596. CRC Press, Boca Raton, Florida, USA. (C) 2021 U. S. Government 


\section{SUMMARY}

In the fall of 2009, the first confirmed North American detection of the European grapevine moth (EGVM) Lobesia botrana (Denis \& Schiffermüller) occurred in Napa County, California, USA. Based on its status as a significant grape pest in other parts of the world, the establishment of EGVM in California presented significant production and export issues for grapes, as well as for other fresh market agricultural commodities. Over the following seven years, an intensive California state-wide survey and area-wide eradication campaign was undertaken in partnership with agricultural officials at local, state and federal levels, university scientists and the wine, table grape and raisin industries. These efforts resulted in a dramatic decline in moth captures in pheromone traps from over 100000 moths in 2010, to one in 2014, and none in 2015. In August of 2016, eradication was declared for all previously infested areas in California. The decision to pursue the eradication effort was based on the limited host range and geographic area of the EGVM infestation, the availability of effective tools for monitoring and control, and the strong support of the affected grape production and export industries. The eradication campaign employed coordinated logistical, regulatory, and technical efforts that included: 1) state-wide-monitoring using a network of pheromone-baited traps and in field monitoring; these findings were recorded in a geographic information system that was used to regularly communicate survey results to programme officials; 2) an area-wide application of mating disruption dispensers to infested vineyards, including use in urban environments within infested zones; 3 ) implementation by coordinators of area-wide insecticide treatments with application timing determined by degree-day modelling for each infested region; 4) a robust regulatory programme that initiated and maintained a quarantine of infested areas that regulated movement of fruit, farming equipment and winery processing waste; 5) an extensive outreach programme to grape growers, wineries, pest control specialists and the public; 6) formation of a technical working group that provided recommendations to the operational programme. An extensive methods development effort supported the programme. This included developing enhanced detection methods for vineyards under mating disruption, testing efficacy and residual control of insecticides, testing mating disruption formulations, evaluating the impacts of winery processing methods on EGVM mortality, developing methods to determine the timing of the development of successive EGVM generations (or biofix) under California conditions to improve degree-day models, developing EGVM rearing methods, testing the quality of pheromone lures and trap monitoring; and a spatial analysis of trapping data to determine programme effectiveness and to analyse invasion pathways.

Key Words: Lepidoptera, pheromone, surveillance, detection, mating disruption, invasive species, grape pests, degree-day models

\section{INTRODUCTION}

The European grapevine moth (EGVM), Lobesia botrana (Denis \& Schiffermüller), is a tortricid moth that has historically been a pest of the Mediterranean regions of Europe, North Africa, and Asia. Recently it has been introduced into the Americas region with first detections in Chile in 2008, California, USA in 2009 and Argentina in 2010 (Ioriatti et al. 2011, 2012; Taret et al., this volume).

Grapevine flowers and berries are favoured hosts for the EGVM. Other hosts include olive flowers, blueberries and plums. Daphne gnidium L., an evergreen shrub from the Mediterranean region, is hypothesized to be the ancestral host (Thiéry and Moreau 2005). Although reported on these other plants, they appear to be used opportunistically only when principal EGVM hosts are in the same environment, though there are some areas in Italy where EGVM populations can sustain themselves exclusively on D. gnidium in the absence of grapevine (Lucchi and Santini 2011). The EGVM has multiple generations a year, starting in the spring from overwintering pupae with 3-4 generations observed in the Mediterranean regions and 3 generations documented in California, with the $3^{\text {rd }}$ generation (and possible a $2^{\text {nd }}$ generation) going 
into winter diapause as pupae (Ioriatti et al. 2012; Cooper et al. 2014). Successive generations target developing stages of grapes, with the first feeding on flower clusters, the second on green berries, and the third inside the bunches after veraison, the change of colour of the grape berries reflecting the onset of ripening. Webbing within the clusters may be apparent, along with excrement and shrivelled berries. Feeding on berries causes direct losses and leads to fungal infections that can cause extensive rot leading to total loss of clusters (Ioriatti et al. 2012).

After overwintering, the first generation starts in spring as eggs and are laid singly on flowers. Larvae hatch and form a feeding nest by webbing together groups of flowers. Larvae from later generations feed on green, ripening, and ripe grapes. Their feeding reduces yield and also affects quality of table grapes or wine grapes, with damage causing bunch rot and mould. Bunch rot causes bad flavours in wine, making heavily infested grapes unusable (Fermaud and Le Menn 1992).

In the fall of 2009, the first confirmed North American detection of the EGVM was made in Napa County, California (Gilligan et al. 2011). Based on EGVM's status as a significant grape pest in other parts of the world, its establishment in California presented significant production and export issues for grapes, as well as for other fresh market agricultural commodities. In response to this EGVM invasion, an extensive California state-wide survey, regulatory programme and area-wide eradication campaign was undertaken in partnership among local, state and federal agricultural officials, university scientists, and the wine, table grape and raisin industries (Cooper el al. 2014).

Here we describe the emergency response programme and results for the detection, regulatory action, initiation of an area-wide programme in 2010 and its coordination, communication and outreach, along with the methods development and research that was initiated to support the programme that led to successful EGVM eradication declared in August 2016.

\section{FIRST DETECTION AND FORMATION OF AN OPERATIONAL PROGRAMME}

On October 7, 2009, the United States Department of Agriculture (USDA) confirmed the presence of the EGVM in Napa County, California for the first time in North America (Gilligan et al. 2011). This area was in the heart of the Napa Valley grape production area close to Napa River, and growers reported extensive damage as well as near $100 \%$ losses caused by direct infestation or spoilage due to cluster rots from several vineyards near the site of the first detection (APHIS 2010). Growers had already reported problems in this area in 2008, with many clusters of fruit being rejected, but the damage was thought to be caused by another tortricid species (APHIS 2010). Larvae collected from the same region in September 2008 were not identified as EGVM at the time, but these were later confirmed also to be EGVM (Gilligan et al. 2011).

While the official recognition did not occur until 2009, given the extensive damage in that year, the damage and identification of larvae from 2008, and its widespread extent revealed by detection trapping in 2010, it is likely that the first EGVM arrived 
in Napa County at least a year or more before 2008, building up over time until extensive vineyard damage was observed.

In 2010, state and federal officials began an emergency response programme to delimit the extent of the infestation and to establish an agricultural quarantine. An extensive pheromone trap monitoring programme was established deploying traps at densities between 6 to 39 traps per $\mathrm{km}^{2}$ throughout vineyards state-wide. Trapping density was dependent on whether trapping occurred within a delimitation area or was part of the detection trapping network (CDFA 2013). More than 60 000, traps were deployed with $>10000$ in Napa and Sonoma counties alone (Fig. 1).

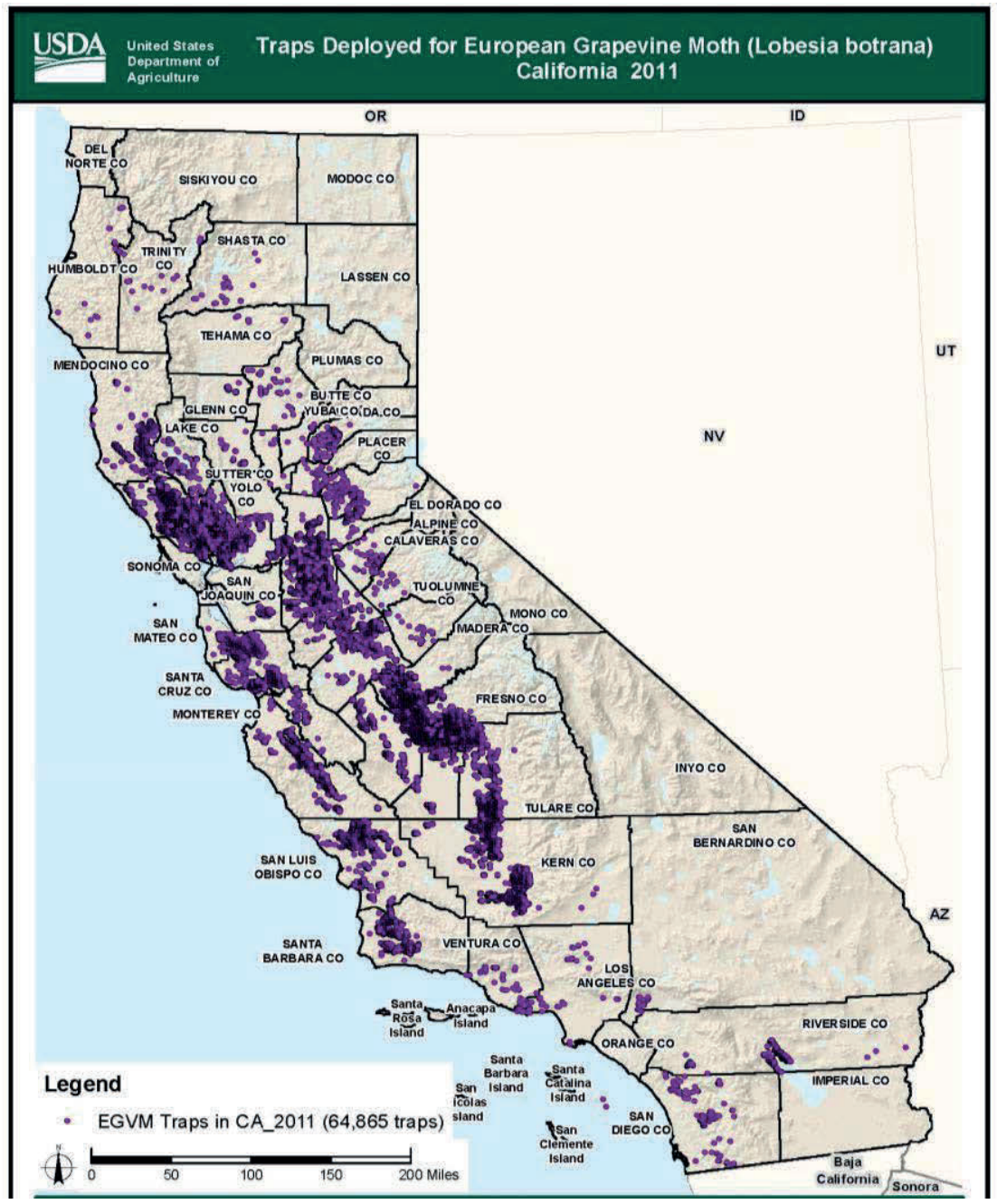

Figure 1. European grapevine moth (EGVM) trap distribution in California counties at the height of the detection effort in the eradication programme (source R. Broadway, USDAAPHIS-PPQ). 
Urban regions in the quarantine area or near grape production areas were also monitored at the rate of 10 traps per $\mathrm{km}^{2}$, and detection trapping was conducted in urban areas outside of quarantine areas at a rate of 2 traps per $\mathrm{km}^{2}$ (CDFA 2013; Cooper et al. 2014).

The USDA-Animal and Plant Health Inspection Service (APHIS) - Plant Protection and Quarantine (PPQ) established a technical working group (EGVMTWG) to make recommendations in support of the emergency response programme. The group was composed of national and international experts in grape pest entomology, area-wide control programmes, viticulture practices and Lepidoptera biology and control. Their primary role was to provide guidance to the programme on the operation of the emergency response and whether eradication of EGVM was feasible.

In 2010, over 100000 male EGVMs were caught in pheromone traps. While the majority of these captures were located in Napa County, there were significant populations in adjacent Sonoma County and few smaller isolated populations elsewhere, which were attributed to movement of grapes to wineries and, in one case, recycled wooden vineyard trellis posts (Lance et al. 2016) (Figs. 2 and 3).
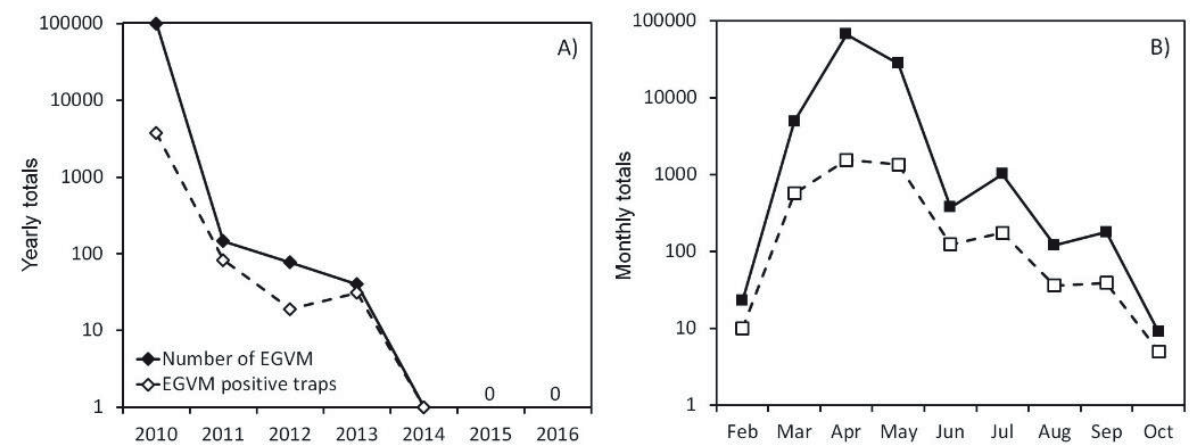

Figure 2. A) Yearly total, 2010 to 2016, and B) 2010 monthly total number of European grapevine moth (EGVM) males caught (solid lines) and total number of traps with at least one EGVM male caught (dashed lines). Y-axes are on a log10 scale.

In response to these detections, a cooperative eradication programme was initiated in 2010 with participation from growers, the wine industry, federal, state, county and University of California authorities and scientists (see Cooper et al. 2014; Lance et al. 2016).

\section{EMERGENCY RESPONSE AND ERADICATION PROGRAMME}

With technical input from the TWG, the EGVM programme initiated a comprehensive regulatory and area-wide eradication effort. The programme consisted of:

1. A state-wide detection network of pheromone traps and vineyard inspections

2. A centralised system to record and map data 
3. Regulations for the movement of plant material, farming and winery equipment, harvested fruit, winery waste, nursery plants, and harvesting bins from and within quarantine areas

4. Area-wide coordinated treatments of mating disruption and insecticide sprays

5. A residential grapevine inspection and treatment programme

6. An extensive outreach and communication effort; and

7. A programme of research and methods development to support the needs of the programme.

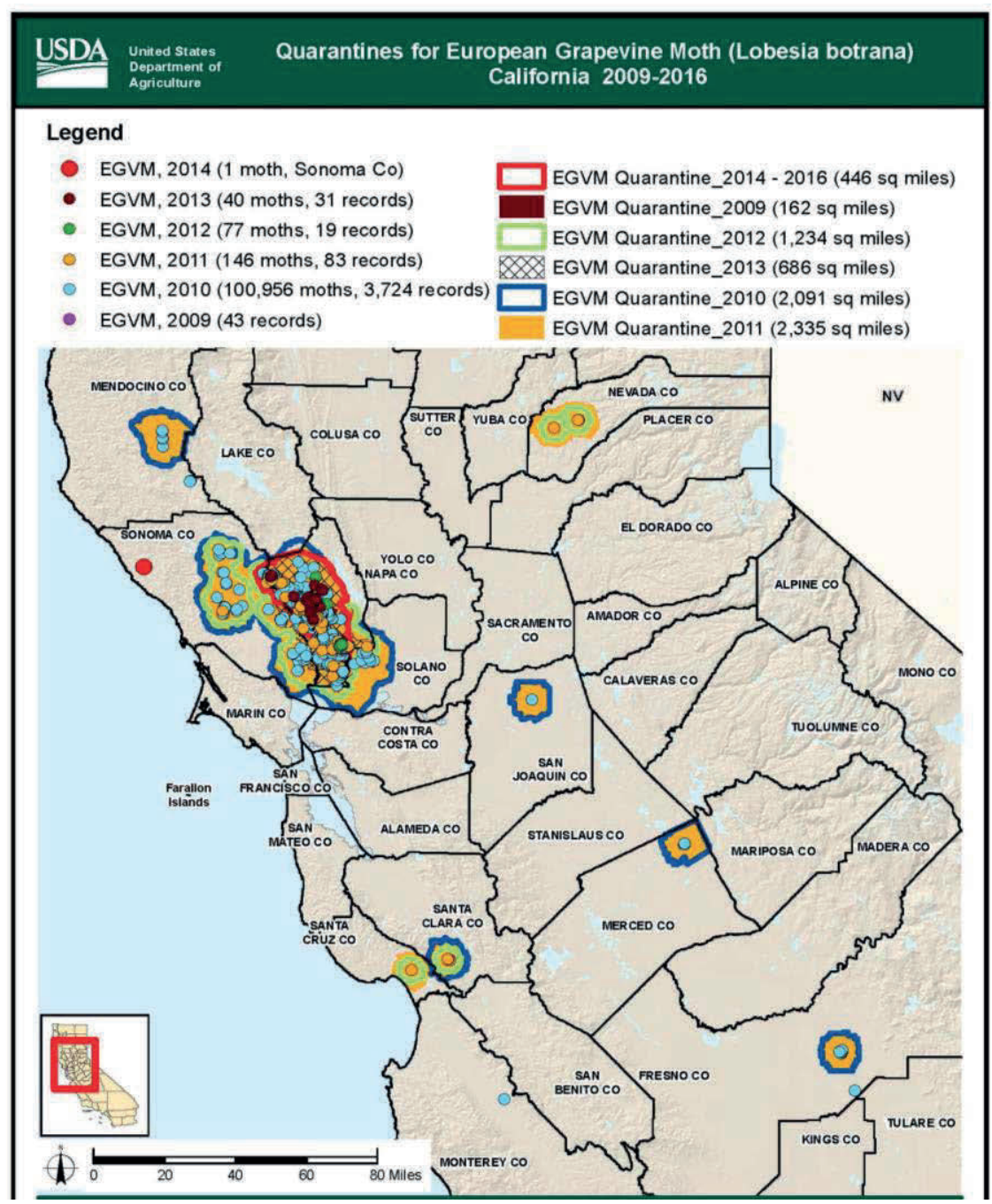

Figure 3. European grapevine moth (EGVM) detections and quarantine areas established in California counties during the eradication programme 2009-2016 (source R. Broadway, USDA-APHIS-PPQ). 


\section{RESEARCH AND METHODS DEVELOPMENT}

The EGVM-TWG, composed of national and international experts, made recommendations to the operational programme on a range of technical issues concerning regulatory action, treatments and detection. While technical information for programme decision-making was available from TWG expertise or from the literature, the TWG also made recommendations on the required research and methods development activities needed to support a programme specific to California, because EGVM was a new pest in North America

Methods development became even more important once a goal of eradication had been established, as this would be one of the first efforts to eradicate populations of this species. A key early decision was to establish a colony of EGVM in the USDAAPHIS-PPQ quarantine facility at the APHIS laboratory in Cape Cod, Massachusetts. Later a second colony was established in a containment laboratory at the University of California at Davis, California. These two colonies supported the important research goals by providing material for research on treatment methods and other mitigation methods.

Other research work included developing enhanced detection methods for vineyards under mating disruption, testing efficacy and residual control of insecticides, testing mating disruption formulations and pheromone lures, evaluating EGVM infestation in other host plants besides grape, assessing the impacts of winery processing methods on EGVM mortality, validation of degree-day models for California conditions, developing EGVM rearing methods, and a spatial analysis of trapping data to determine programme effectiveness and to analyse invasion pathways (Lucchi et al. 2012; Van Steenwyk et al. 2013; Varela et al. 2013; Cooper et al. 2014; Daugherty et al. 2015).

Since EGVM represented a new invasive pest in California, a critical activity was the testing and validation of EGVM degree-day models from Europe for use in California (see EGVM models described in CABI 2019). This information was used to determine the start of the first spring generation, or biofix, to set the timetable for placement of traps, to determine treatment schedules and for decision-making for other programme operations requiring an accurate assessment of the EGVM life cycle in California.

Especially since EGVM was not yet widespread, an accurate model was needed to conduct programme operations throughout the state. The use of degree-day models became increasingly important as the programme progressed and EGVM populations were reduced, leaving fewer population cues available to make treatment decisions (Varela et al. 2011; Cooper et al. 2014).

\section{DETECTION AND SURVEILANCE PROGRAMME}

Traps were installed across the state in all grape growing areas (Fig. 1). Trapping levels varied across the state depending on the infestation levels, availability of host plants, as well as programme resources. In the first quarantine areas in Napa, Sonoma and Solano counties, traps were deployed in commercial vineyards at a density of 39 traps per $\mathrm{km}^{2}$ and in residential areas at 10 traps per $\mathrm{km}^{2}$ within a $5-\mathrm{km}$ radius from a 
detection (CDFA 2013). Beyond $5 \mathrm{~km}$ from a quarantine, traps were deployed at 10 traps per $\mathrm{km}^{2}$ in commercial vineyards and 2 traps per $\mathrm{km}^{2}$ in residential areas (CDFA 2013).

For all commercial vineyards outside of quarantine areas, traps were deployed at 10 traps per $\mathrm{km}^{2}$ (CDFA 2013). An additional protocol for detection trapping was to deploy traps at grape processing facilities in unregulated counties that received grapes from quarantine areas. These areas, determined to be "high hazard", were trapped within $0.8 \mathrm{~km}$ of the facility at 10 traps per $\mathrm{km}^{2}$. There were 22 wineries in nine unregulated counties that fit these criteria (CDFA 2013).

In the first year of the programme, there was some testing of the EGVM pheromone blend, loading and emission rates. The resulting data supported the programme decision to use the single-component pheromone blend of $(Z, E)$-7-9dodecadienyl acetate loaded at $1 \mathrm{mg}$ on rubber septa. The septa lures were produced by a USDA laboratory the first year and afterward under commercial contract (CDFA 2013; Cooper et al. 2014).

Although different delta trap size and styles could be used for EGVM, a red paper delta trap was selected because, in part, the state had a large surplus supply of these traps available from another programme and because the red colour would limit the number of bees trapped as by-catch. These traps have all interior surfaces coated with biotac glue.

Traps were hung at canopy height, approximately one meter above the ground on vineyard wires or on vines at the end of rows along major vineyard roadways, permitting easy access for trappers. Traps in residential areas were placed on grapes if available or on secondary hosts such as Prunus spp. or olive. Vineyard traps were put into the field before bud break based on predictions by degree-day models, but in practice for northern California, the programme worked to have all traps deployed at the start of the growing season-near the end of February or early March. Traps were kept in the field until the end of September (CDFA 2013).

Traps were inspected biweekly and brought into the laboratory for identification of moths at local offices and suspected L. botrana finds were submitted to the California Department of Food and Agriculture (CDFA) State Diagnostics Laboratory for confirmation. Finds in a new area triggered an immediate establishment of a quarantine area, initiation of suppression treatments, and a new cycle of delimitation trapping in that area. Trap data were recorded with GPS coordinates for purposes of visualization with mapping programmes. These maps were provided to programme personnel to make operational decisions.

Included in the programme was a pre-season assessment of contracted lure quality, analysis of lure emission rates to determine trap service intervals, ongoing training to programme personnel regarding trap placement, and training to identify L. botrana and other moths in traps. Dead moths from a laboratory colony were used to seed traps in the field for quality checks on training and trap-checking frequency.

At the peak of the programme in 2011 , there were 11 counties with detections for a quarantine area totalling 604763 ha. Within this area, there were 325000 ha of vineyards with $>60000$ traps deployed over all the vineyards in California (Fig. 2). Trapping has continued post-eradication at levels similar to those used throughout the programme in areas outside of quarantine (APHIS 2016). 


\section{REGULATORY PROGRAMME QUARANTINE AND DELIMITATION}

State and federal quarantine areas were established around every EGVM detection consisting of an 8-kilometer radius. The standard of detection to establish a quarantine was defined as two moths found within $5 \mathrm{~km}$, or a single larva or egg (CDFA 2013; Cooper et al. 2014). With the detection of an additional life stage, delimitation trapping would begin with placement of 39 traps per $\mathrm{km}^{2}$ in the central $2.6 \mathrm{~km}^{2}(1$ square mile) and at 10 traps per $\mathrm{km}^{2}$ in the $10-\mathrm{km}^{2}$ area surrounding the detection. An EGVM detection in the area surrounding the detection would trigger expansion of the quarantine to include the new find area (CDFA 2013).

To allow the movement of fruit from quarantine areas at harvest, requirements included checking compliance with previous control treatments, an inspection of fruit before harvest, covering truckloads with tarps and restricting the movement and processing of fruit to within an existing EGVM quarantine area. To further mitigate the risk of moving infested fruit, truckloads of grapes waiting at a winery needed to be processed within a specified short time period after arrival.

Early in the infestation it became clear that there was an association between the locations of outbreaks and where wine grapes were processed. Though it was unknown if standard grape processing techniques and handling of waste products would mitigate the risk of spreading EGVM, the programme implemented controls on the movement and processing of grapes for making wine, while concurrently evaluating EGVM mortality during wine-making.

Specifically, a series of experiments were conducted to determine if grape crushing, pressing and the fermentation process would kill EGVM larvae or pupae (see Varela et al. 2013; Smith et al. 2013; Cooper et al. 2014). This work showed that significant numbers of larvae could survive grape processing on harvesting and transport equipment, on green wastes from destemming, crushing and pressing, and on winery equipment (Smith et al. 2013).

This work led to requirements for winery-waste and green-waste management and treatment by composting at a regulated composting operation, on-site deep burial, or other destruction methods such as burning or heat treatment. Alternatively, if the grapes, clusters or other green wastes for white wine processing (that were not fermented) were pressed at 2.0 bars, the resulting winery waste could be returned to the original vineyard. Grapes in must (crushed grapes in juice) and pomace (a waste product after fermentation of red varieties) were not regulated as research showed that the process of fermentation would kill all EGVM life stages (Smith et al. 2013; Cooper et al. 2014).

Under conditions determined by the TWG, previously quarantined areas became eligible for deregulation after several conditions were met including: mating disruption used for a full year following the detection; insecticide treatments applied for the first and second generations for two years following the year of detection; a visual survey conducted in vineyards treated with mating disruption; mating disruption not used in the last two generations before deregulation; and trap density increased to 39 traps per $\mathrm{km}^{2}$ in the years after mating disruption was removed. If no EGVM life stages were detected for six full generations after the last capture in the area, it could be removed from regulation (Cooper et al. 2014; APHIS 2015, 2016). 


\section{TREATMENTS}

Commercial vineyards, residential plantings of grapes and other hosts were treated within $500 \mathrm{~m}$ of a EGVM detection. Treatments consisting of timed insecticide applications, mating disruption and fruit stripping were made on a coordinated areawide basis. Treatments were continued for two full growing seasons following the year of detection (Cooper et al. 2014). University of California extension personnel using degree-day and crop stage reporting recommended when treatments should be applied.

The cooperative programme employed grower liaisons to help with outreach, to coordinate treatments in each county and to work with growers. These individuals, licensed pest control advisers, worked closely with all affected growers and operational programme personnel. As this was a voluntary programme, the grower liaison's work was crucial to ensure high levels of participation and were a key to successful eradication (Cooper et al. 2014).

\subsection{Mating Disruption}

In the California programme, mating disruption played a principal role in the management of EGVM in commercial vineyards. Plastic hollow-tube dispensers loaded with EGVM pheromone ((E,Z)-7,9-dodecadien-1-yl acetate (ISOMATE $E G_{V M}^{\mathrm{tm}}$ ) (Lance et al. 2016) were set out in all grape-bearing areas within a $500 \mathrm{~m}$ radius of any detection at the rate of 494 dispensers per hectare (Cooper et al. 2014; Lance et al. 2016). The goal was to deploy the dispensers before bud break, which was predicted by degree-day models. In practice, this occurred in February in the Napa County region.

Treatments with mating disruption were applied for at least two full flights following a moth detection. When moths were trapped in an area during the first flight of a season, mating disruption treatments were applied at that time. If moths were trapped in the second flight, mating disruption applications were made early in the following spring. A single pheromone application was sufficient for the season as field testing pheromone emission rates determined that these dispensers remained viable for the entire season under Napa conditions.

At the peak of ECVM suppression in 2012, mating disruption was used on 9340 ha in the core of the infested region of Napa and Sonoma counties (Cooper et al. 2014). Mating disruption was also used as a component of the residential treatments, with a peak of over 3000 properties treated in 2011 (Cooper et al. 2014).

Because the same pheromone was used for monitoring, widespread use of mating disruption caused monitoring programme traps to be less effective within treated areas. This was the primary reason the TWG recommended using mating disruption for a relatively short period of time as well as removing it for a period prior to deregulation to determine that an area was free of the EGVM. It also highlighted the need to test alternative attractants for their potential under conditions of mating disruption.

The use of mating disruption in combination with insecticides was recommended because the use of multi-tactic independent control measures in area-wide control 
programmes can be more effective by increasing the likelihood of Allee effects (Yamanaka and Liebhold 2009) and by helping to cover for possible gaps in treatment and for control of moths coming from undetected EGVM populations from nearby areas (Cardé, this volume; Liebhold et al. 2016).

The recent eradication of pink bollworm from the south-western USA and northern Mexico (Staten and Walters, this volume) is a convincing demonstration of this integrated approach and was considered successful using three or more control tactics on an area-wide basis (Tabashnik et al. 2010; Evenden 2016; Lance et al. 2016).

\subsection{Insecticide Treatments}

The programme specified coordinated treatments with insecticides made during the first and second generations for at least two complete growing seasons following the year of the detection. For the two counties at the heart of the infestation (Napa and Sonoma) a grower liaison was contracted to coordinate treatments in commercial areas. Degree-day models were used to target eggs and young larvae at the start of the first and second generations (Varela et al. 2011; Cooper et al. 2014). In practice, this resulted in a three-week treatment window for each flight. By the third generation, grape bunch closure can limit the effectiveness of insecticides so treatments to target the third generation were not recommended.

Materials used included conventional foliar insecticides: the growth regulator methoxyfenozide, and diamide chlorantraniliprole; other materials used included abamectin as well as Bacillus thuringiensis (Bt) and spinosyns for organic production vineyards (Daugherty et al. 2015). Treatments applied to commercial areas, while voluntary, had participation rates as high as $80 \%$, with a peak of 12306 ha treated in 2012 in Napa and Sonoma counties (Cooper el al. 2014). To meet eradication programme recommendations these treatments continued for several years during periods when there were no significant detections and when growers did not suffer any losses or direct impacts of EGVM infestation. The fact that participation rates were high during this period, and application costs were paid by individual growers, is a testament to the effectiveness of the coordination and the outreach provided to growers about programme needs. Personnel of CDFA coordinated and applied treatments in residential areas. CDFA officials were supported locally by the offices of the county Agricultural Commissioners, particularly as related to outreach at public meetings and consultation to gain permission from homeowners. These treatments also had a high rate of participation. They included application of $B t$, fruit stripping and some uses of mating disruption (CDFA 2010a; Cooper et al. 2014).

\section{OUTREACH AND COMMUNICATION}

There was an extensive programme of outreach to grape growers, industry professionals, wineries and grape processing facilities, and the public at large. The outreach programme had several objectives. These included providing accurate technical information about the pest, helping to encourage participation with the 
programme and coordination of the area-wide programme treatments, and gaining public support for the eradication programme activities. As the EGVM was a new pest to California, communicating accurate pest biology and control information to growers, pest control advisers and grower liaisons, industry representatives and programme officials was a critical need and provided the linkage between the research effort and the operation of the eradication campaign (Cooper et al. 2014).

Information was provided through grower meetings and field days, public meetings, an email newsletter, University of California websites, communications with the grower liaisons, and university extension personnel, as well as local, state and federal government media campaigns using social media, blogs, mailings and local advertising (Fig. 4) (CDFA 2010b; Cooper et al. 2014; APHIS 2017; CDFA 2017; Napa County 2017; University of California 2017).
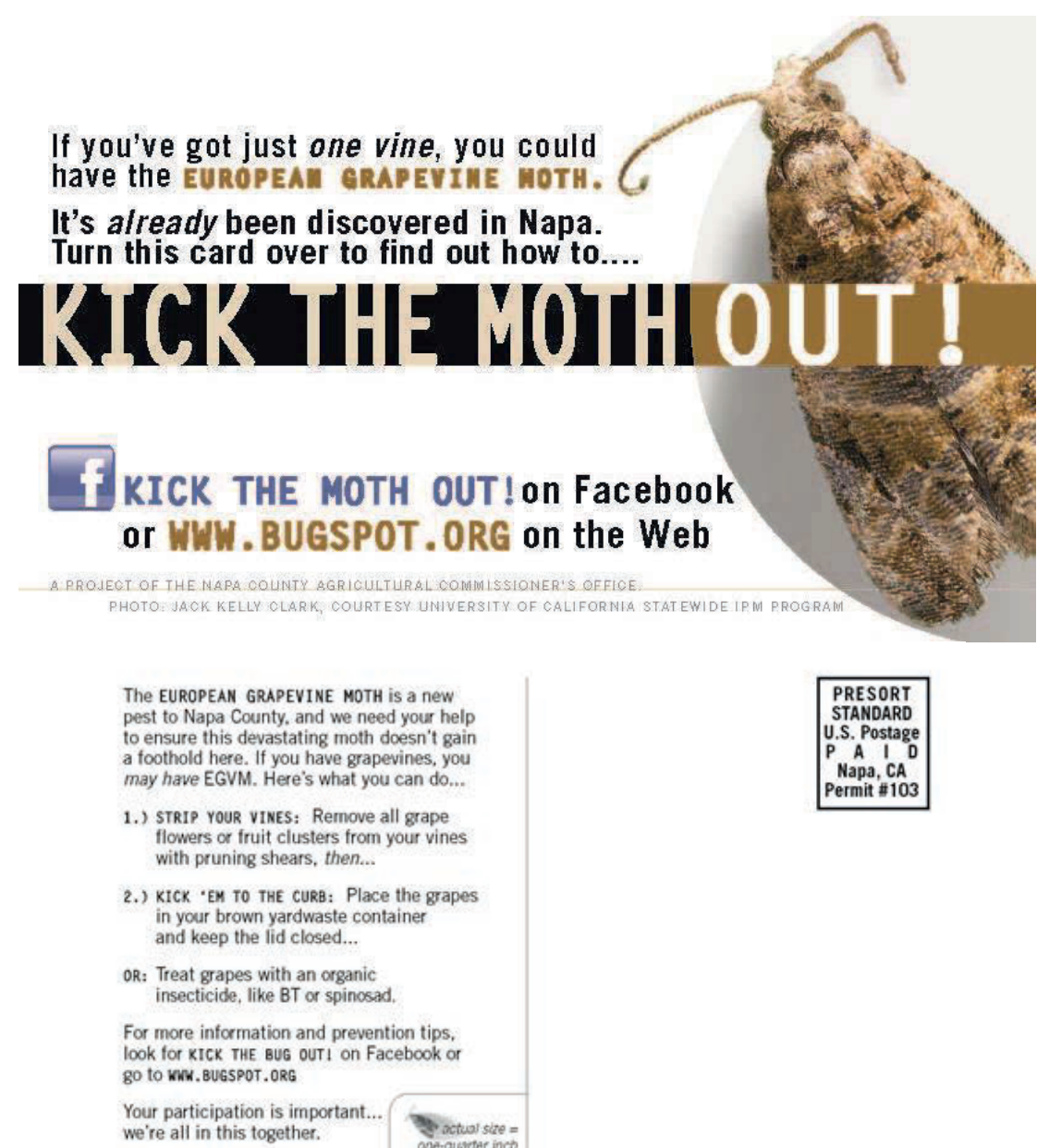

Figure 4. The European grapevine moth (EGVM) eradication outreach as a postcard from Napa County Agricultural Commissioner's office (used with permission of Napa County). 
The outreach campaign was deemed critical to achieve programme success (Cooper et al. 2014; Daugherty et al. 2015). Indeed, in comparison to another recent unsuccessful eradication campaign, public support and engagement was considered essential for programme success (Zalom et al. 2013; Lance et al. 2016).

\section{PROGRAMME RESULTS AND ERADICATION DECLARATION}

The combined efforts of the programme resulted in a dramatic decline in moth captures from over 100000 moths in 2010, to one moth in 2014, and no moth captures or larval finds by 2015 (Figs. 2 and 3). Using a step-wise process, the programme proceeded with deregulating large contiguous blocks once they met free-from-EGVM standards. This was a conservative approach and meant that some areas that had been free from EGVM for longer than required by the programme deregulation standards were kept under regulated status until larger associated geographic areas met the freefrom-EGVM standard. With this approach, deregulation would not occur in a patchwork fashion (APHIS 2015).

In August of 2016, eradication was declared from all previously infested areas in California (CDFA 2016). At that time, the USA was declared free from this pest. At the end of a full 2017 trapping season, there have been no EGVM detections in the USA for over three years and all of the previously EGVM infested California grape production areas have been free from EGVM between 3-5 years depending on their location.

\section{POST ERADICATION PHASE AND ONGOING VIGILANCE.}

While the eradication campaign against EGVM was accomplished in a relatively short period, and grape producers in California can be confident that eradication has been achieved, the EGVM programme and industry officials drew up plans to conduct a post-eradication campaign for a period of at least three years after the eradication declaration (APHIS 2016).

Like other successful USA eradication campaigns (APHIS 2009; Cardé, this volume), adding a period of extra vigilance after an area is eradicated is considered a sensible safeguard. Early detection of any new EGVM incursions will be smaller and far cheaper to contain and eliminate then if the detection is made later at a time when the detection network has been reduced and fewer traps are deployed.

The pathway by which EGVM entered North America is still unknown, and the opportunities and conditions regarding international trade and possible entry pathways may remain the same (Cooper et al. 2014). The EGVM is a pest on the move and has been expanding its range. It is now present in parts of South America and is causing significant problems, which means there are additional possible invasion sources beyond European and Mediterranean countries (Ioriatti et al. 2012).

Besides the need to continue a post-eradication phase, there is a need for additional research and programme activity to enhance safeguarding of the USA grape industry. This work includes development of alternatives to pheromone detection methods that work under mating disruption treatment, such as kairomones or alternate pheromone 
blends. Work is underway to analyse detection data from the area-wide control programme using geospatial modelling techniques to evaluate landscape patterns of the invasion and to model trap-grid detection efficiency to help design lower-cost, long-term future detection strategies, in the post-eradication phase.

A second need is to conduct an economic analysis on the costs and benefits of continued monitoring for EGVM after the post-eradication phase has ended. This should include an analysis of possible harm of other potentially damaging economic grape pests not yet present in California and other North American grape production areas that may use similar pathways used by the EGVM. These include the European grape berry moth Eupoecilia ambiguella (Hübner), the grape tortrix Argyrotaenia ljungiana (Thunberg), the grape berry moth Paralobesia viteana (Clemens), the honeydew moth Cryptoblabes gnidiella (Millière), and others.

Lastly, there should be ongoing outreach to growers, field workers, trappers, and pest control advisers so they can continue to recognize the EGVM and for ongoing training by personnel involved in EGVM and other grape pest surveys.

\section{ACKNOWLEDGEMENTS}

Members of the EGVM Technical Working Group of APHIS-PPQ are Bruno Bagnoli, Department for Innovation in Biological, Agro-Food and Forest Systems, University of Tuscia, via San Camillo de Lellis, 01100 Viterbo, Italy; Ring T. Cardé, University of California, Riverside, California; Monica Cooper, University of California Cooperative Extension, Napa, California; Claudio Ioriatti, Istituto Agrario San Michele all'Adige (IASMA), Italy; David Lance (retired), USDA-APHIS-PPQ, Buzzards Bay, Massachusetts; Andrea Lucchi, Dipartimento di Scienze Agrarie, Alimentari ed Agroambientali, Pisa, Italy; Vic Mastro (retired), USDA-APHIS-PPQ, Buzzards Bay, Massachusetts; Gonçal Barrios, Departament d'Agricultura, Tarragona, Spain; Luis Sazo, University of Chile, Santiago de Chile, Chile; Gregory Simmons, USDA-APHIS-PPQ, Salinas, California; Robert Steinhauer, Wineland Consulting, LLC, St. Helena, California; and Lucia Varela, University of California Cooperative Extension, Santa Rosa, California. We thank Thomas Greene, USDAAPHIS-PPQ for literature research.

\section{REFERENCES}

(APHIS) Animal and Plant Health Inspection Service. 2009. Minimum standards for pink bollworm post-eradication. USDA. Accessed October 30, 2017.

(APHIS) Animal and Plant Health Inspection Service. 2010. Final report of the international technical working group for the European Grape Vine Moth (EGVM) in California, February 10, 2010. USDA.

(APHIS) Animal and Plant Health Inspection Service. 2015. Report of the international technical working group for the European grapevine moth program. USDA.

(APHIS) Animal and Plant Health Inspection Service. 2016. European grapevine moth post-eradication response guidelines. USDA.

(APHIS) Animal and Plant Health Inspection Service. 2017. European grapevine moth, USDA-APHIS Hungry Pest Website, Accessed October 22, 2017.

(CABI) Centre for Agriculture and Bioscience International. 2019. Datasheet Lobesia botrana (European grapevine moth). Invasive Species Compendium. 
(CDFA) California Department of Food and Agriculture. 2010a. News Release \#10-050: Fruit removal treatment for European grapevine moth scheduled for Solano county.

(CDFA) California Department of Food and Agriculture. 2010b. European grapevine moth (Lobesia botrana).

(CDFA) California Department of Food and Agriculture. 2013. European grapevine moth (EGVM) detection trapping guidelines fiscal year 2012-13 and fiscal year 2013-14.

(CDFA) California Department of Food and Agriculture. 2016. European grapevine moth eradicated from California. Agricultural officials confirm eradication of grape pest, lift quarantine restrictions.

(CDFA) California Department of Food and Agriculture. 2017. European grapevine moth (EGVM). Accessed October 22, 2017.

Cooper, M., L. G. Varela, R. Smith, D. Whitmer, G. S. Simmons, A. Lucchi, R. Broadway, and R. Steinhauer. 2014. Managing newly established pests: Growers, scientists and regulators collaborate on European grapevine moth program. California Agriculture 68: 125-133.

Daugherty, M., M. L. Cooper, G. S. Simmons, R. J. Smith, and L. G. Varela. 2015. Progress made on control of European grapevine moth: Present status and next steps. CAPCA Adviser Magazine, December, 18(6): 54-56.

Evenden, M. 2016. Mating disruption of moth pests in integrated pest management. A mechanist approach, pp. 365-393. In J. D. Allison, and R. T. Cardé (eds.), Pheromone communication in moths: Evolution, behavior and application. University of California Press, Berkeley, California, USA.

Fermaud, M., and R. Le Menn. 1992. Transmission of Botrytis cinerea to grapes by grape berry moth larvae. Phytopathology 82: 1393-1398.

Gilligan, T. M., M. E. Epstein, S. C. Passoa, J. A. Powell, and J. W. Brown. 2011. Discovery of Lobesia botrana [(Denis \& Schiffermüller)] in California: An invasive species new to North America (Lepidoptera: Tortricidae). Proceedings of the Entomological Society of Washington 113: 14-30.

Ioriatti, C., G. Anfora, M. Tasin, A. De Cristofaro, P. Witzgall, and A. Lucchi. 2011. Chemical ecology and management of Lobesia botrana (Lepidoptera: Tortricidae). Journal of Economic Entomology 104: 1125-1137.

Ioriatti, C., A. Lucchi, and L. G. Varela. 2012. Grape berry moths in western European vineyards and their recent movement into the New World, pp. 339-359. In N. J. Bostanian, C. Vincent, and R. Isaacs (eds.), Arthropod management in vineyards: Pests, approaches, and future directions. Springer, Dordrecht, The Netherlands.

Lance, D. R., D. S. Leonard, V. C. Mastro, and M. L. Walters. 2016. Mating disruption as a suppression tactic in programs targeting regulated lepidopteran pests in US. Journal of Chemical Ecology 42: 590 605 .

Liebhold, A. M., L. Berec, E. G. Brockerhoff, R. S. Epanchin-Neill, A. Hastings, D. A. Herms, J. M. Kean, D. G. McCullough, D. M. Suckling, P. C. Tobin, and T. Yamanaka. 2016. Eradication of invading insect populations: From concepts to applications. Annual Review of Entomology 61: 335352.

Lucchi, A., and L. Santini. 2011. Life history of Lobesia botrana on Daphne gnidium in a Natural Park of Tuscany. IOBC/WPRS Bulletin 67: 197-202.

Lucchi, A., B. Bagnoli, M. L. Cooper, C. Ioriatti, and L. G. Varela. 2012. The successful use of sex pheromones to monitor and disrupt mating of Lobesia botrana in California. In Abstracts IOBC/WPRS Working Group meeting on "Pheromones and other semio-chemicals in integrated production", October 1-5, 2012 in Bursa, Turkey.

Napa County. 2017. European grapevine moth. County of Napa, California, USA. Accessed October 22, 2017.

Smith, R. J., M. L. Cooper, and L. G Varela. 2013. Determining the threat of dispersal of Lobesia botrana larvae in infested grapes processed for wine making. Practical Winery and Vineyard: 73.

Tabashnik, B. E., M. S. Sisterson, P, C. Ellsworth, T. J. Dennehy, L. Antilla, L. Liesner, M. Whitlow, R. T. Staten, J. A. Fabrick, and G. C. Unnithan. 2010. Suppressing resistance to Bt cotton with sterile insect releases. Nature Biotechnology 28: 1304-1307.

Thiéry, D., and J. Moreau. 2005. Relative performance of European grapevine moth (Lobesia botrana) on grapes and other hosts. Oecologia 143: 548-557.

University of California. 2017. UC IPM / Invasive and Exotic Pests / European grapevine moth. Accessed October 22, 2017.

Varela, L. G., M. L Cooper, W. J. Bentley, and R. J. Smith. 2011. Degree-day accumulations used to time insecticide treatments to control 1st generation European grapevine moth. Sonoma County, California, USA. University of California Cooperative Extension Publication. 
Varela, L., A. Lucchi, B. Bagnoli, G. Nicolini, and C. Ioriatti. 2013. Impacts of standard wine-making process on the survival of Lobesia botrana larvae (Lepidoptera: Tortricidae) in infested grape clusters. Journal of Economic Entomology 106: 2349-2353.

Yamanaka, T., and A. M. Liebhold. 2009. Mate-location failure, the Allee effect, and the establishment of invading populations. Population Ecology 51: 337-340.

Zalom, F., J. Grieshop, M. Lelea, K. Jennifer, J. K. Sedell. 2013. Community perceptions of emergency responses to invasive species in California: Case studies of the light brown apple moth and the European grapevine moth. Cooperative Agreement \#10-8100-1531-CA. USDA-APHIS \& University of California, Davis, California, USA. Accessed October 30, 2017. 